https://doi.org/10.1007/s11678-021-00642-z

Received: 7 February 2021

Accepted: 30 March 2021

Published online: 3 May 2021

(c) The Author(s) 2021
Obere Extremität 2021 1 16:198-202

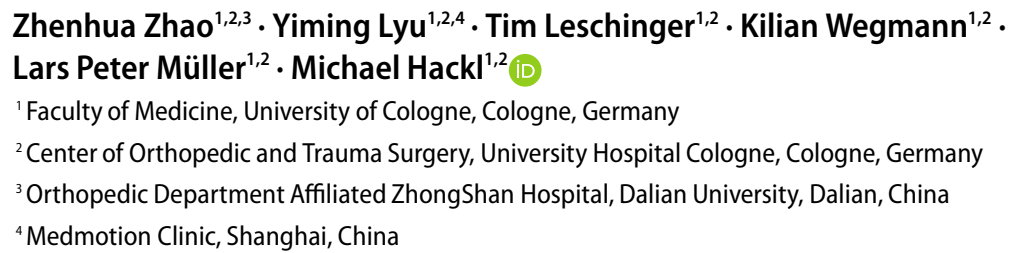

\section{Imaging diagnosis of radial head fractures-evaluation of plain radiography vs. CT scans}

\section{Methods}

with an with an equally complex biomechanical structure. In $30-56 \%$ of adult elbow fractures and $20 \%$ of all acute elbow injuries, the radial head is found to be injured [1]. Furthermore, between $1.7 \%$ and $5.4 \%$ of all adult fractures involve the radial head [2].

The Mason classification is widely used for radial head fractures. It proposes three types: Type 1 fractures are non-displaced fractures; type 2 fractures are displaced two-part fractures; and type 3 fractures are comminuted fractures [3]. Later, a type 4 fracture was proposed by Johnston, who defined this new type of fracture as any radial head fracture accompanied by elbow dislocation [4]. Radial head fractures are diagnosed through plain radiography of the elbow in an anteroposterior, a lateral, and a radial head view. An additional computed tomography (CT) scan is considered to be helpful for assessing the severity of the injury in greater detail [5]. However, to date, no data are available that compare the accuracy of plain radiography and CT scans for diagnosing radial head fractures.

Therefore, this study analyzed the classification according to Mason, the percentage of articular involvement, and the fragment size of radial head fractures separately with plain radiographs and CT images to evaluate possible differences between the two diagnostic measures.

\section{Patient selection and inclusion criteria}

In total, 52 consecutive cases of isolated radial head fractures were selected from the database of the University Medical Center of Cologne. The median age of the patients included in the study was 41 years (range 23-80); 36 (69\%) were female and $16(31 \%)$ were male. The software Agfa IMPAX EE (Agfa Health
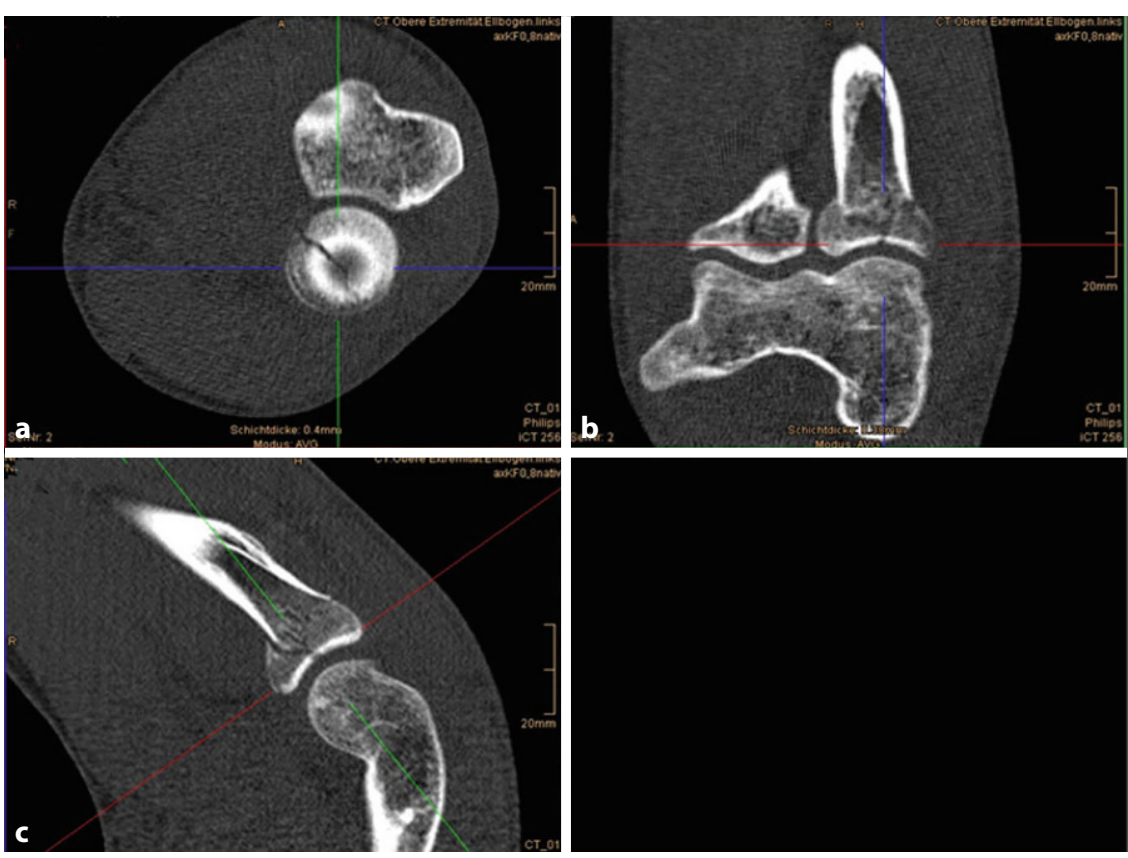

Fig. $1 \Delta$ Computed tomography scan of a left elbow with a radial head fracture. a Axial plane; b coronal plane; c sagittal plane 


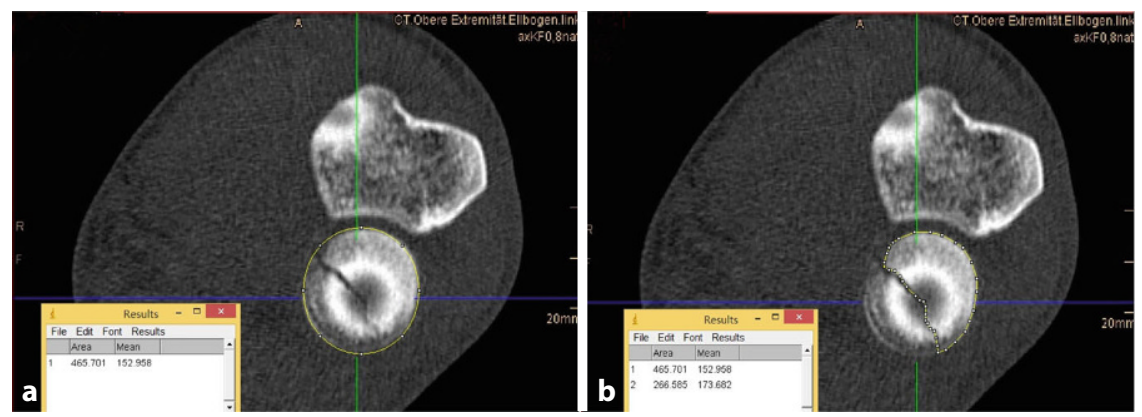

Fig. $2 \Delta$ Measurement of articular fracture involvement. Computed tomography scan of a left elbow with Mason type I fracture (axial view). a The total area of the articular surface of the radial head is marked (yellow line). $\mathbf{b}$ The intact part of the articular surface of the radial head is marked (yellowline)
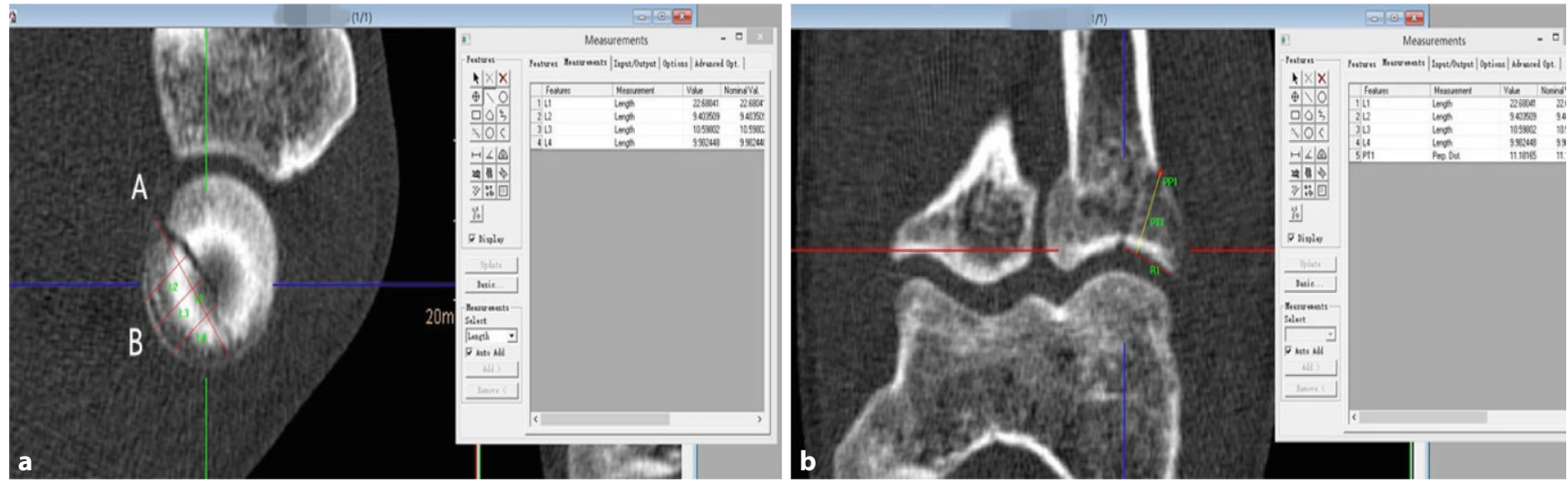

Fig. $3 \Delta$ Measurement of fragment size. Computed tomography scan of a left elbow in an axial view. a Measurement of the length $(A)$ and width $(B)$ of the fracture fragment. $\mathbf{b}$ Measurement of the height of the fragment

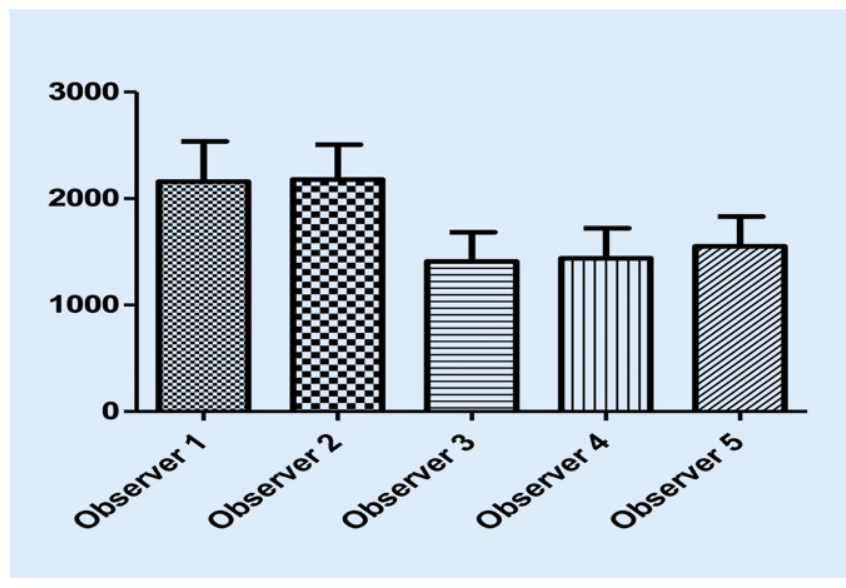

Fig. $4 \Delta$ Size of the largest fragment in $\mathrm{mm}^{3}$. Observers $3-5$ underestimated the fragment sizes when compared with the computed tomography measurements of observers 1 and $2(p<0.01)$

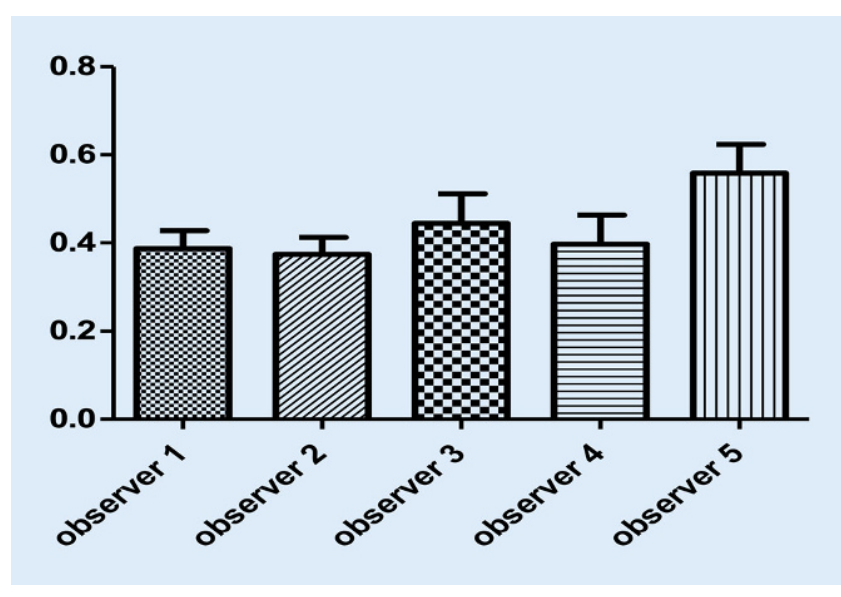

Fig. $5 \Delta$ Involvement of the articular surface (\%). Observers 3-5 tended to overestimate the involvement of the articular cartilage. Only the results for observer 5 were statistically significant $(p<0.01)$ head fractures according to Mason [3] and measured the percentage of articular involvement and the size of the largest fracture fragment with CT scans on two separate occasions. As shown in • Fig. 1 , a CT image of the elbow is displayed in four quadrants. There are three axes (displayed in red, green, and blue) representing the axial, coronal, and sagittal planes, respectively (• Fig. 1).

To measure the percentage of articular involvement, the software of Image $\mathrm{J}$ (National Institute of Health, Bethesda, MD, USA) was used. First, the area of the radial head articular surface was marked and measured in an axial view (• Fig. 2a). Then, the area of the intact part of the radial head articular surface was marked (- Fig. 2b). By dividing the area of the intact part of the radial head by the total area of the radial head articular surface, the 
Obere Extremität 2021 · 16:198-202 https://doi.org/10.1007/s11678-021-00642-z

(c) The Author(s) 2021

\section{Z. Zhao $\cdot$ Y. Lyu $\cdot$ T. Leschinger $\cdot$ K. Wegmann $\cdot$ L. P. Müller $\cdot$ M. HackI}

\section{Imaging diagnosis of radial head fractures_evaluation of plain radiography vs. CT scans}

Abstract

Background. Radial head fractures represent a common pathology that can cause permanent disability, especially if not treated correctly. Plain radiographs as well as computed tomography (CT) scans represent important diagnostic measures. The specific differences between these two imaging modalities with regard to diagnosis of radial head fractures have not been evaluated to date.

Objective. This study aimed to compare estimations of fracture classification, percentage of articular fracture involvement, and fragment sizes through plain radiography with CT scan evaluations.

Methods. A total of 52 consecutive cases of isolated radial head fractures with plain radiographs and $\mathrm{CT}$ scans were evaluated retrospectively. Two observers analyzed the fracture classification according to Mason, the percentage of articular fracture involvement, and the size of the largest fracture fragment by means of CT. Three trauma surgeons estimated these parameters through blinded plain radiographs. Intra- and inter-observer reliability were evaluated.

Results. The CT scan evaluations showed high intra- and inter-observer reliability without significant differences between the two observers. X-ray estimations of fracture classifications showed only fair agreements. Moreover, the estimations of articular fracture involvement and fragment sizes differed significantly from the CT scan evaluations. While the fragment size tended to be underrated, the articular involvement tended to be overrated.

Conclusion. This study shows that plain radiographs often provide unreliable information regarding classification, articular involvement, and fragment sizes of radial head fractures. When in doubt, an additional CT scan should be carried out to assess the injury in greater detail.

Keywords

Radius fractures $\cdot$ X-rays $\cdot$ Computed tomography $\cdot$ Diagnostics $\cdot$ Radiography

\section{Bildgebende Diagnostik von Radiuskopffrakturen - konventionelle Röntgen- versus CT-Aufnahmen}

\section{Zusammenfassung}

Hintergrund. Radiuskopffrakturen stellen eine häufige pathologische Veränderung dar, die zu bleibenden Einschränkungen führen kann, insbesondere bei insuffizienter Therapie. Konventionelle Röntgenaufnahmen sowie die Untersuchung per Computertomographie (CT) sind wichtige diagnostische Mittel. Die spezifischen Unterschiede dieser beiden bildgebenden Verfahren bezüglich der Diagnostik von Radiuskopffrakturen wurden bisher nicht untersucht.

Zielsetzung. Diese Studie hatte das Ziel, die Einschätzung der Frakturklassifikation, der Gelenkflächenbeteiligung und der Fragmentgröße anhand konventioneller Röntgenaufnahmen mit den Ergebnissen einer CT-Untersuchung zu vergleichen. Methoden. Es wurden 52 aufeinanderfolgende Fälle von Radiuskopffrakturen, zu denen sowohl konventionelle Röntgenaufnahmen als auch CT-Untersuchungen vorhanden waren, retrospektiv untersucht. Dabei beurteilten 2 Untersucher die Frakturklassifikation nach Mason, das prozentuale Ausmaß der beteiligten Gelenkfläche und die Größe des größten Fragments anhand von CT-Daten. Anhand verblindeter Röntgenaufnahmen schätzten 3 Unfallchirurgen diese Parameter. Dann wurde die Intra-/Inter-ObserverReliabilität untersucht.

Ergebnisse. Die Beurteilungen anhand der CT-Daten zeigte eine hohe Intra- und Inter-Observer-Reliabilität ohne signifikante Unterschiede zwischen beiden Untersuchern. Die Einschätzungen anhand der Röntgenaufnahmen wiesen nur eine mäßige Übereinstimmung auf. Die Fragmentgröße wurde tendenziell unterschätzt, während das prozentuale Ausmaß der betroffenen Gelenkfläche eher überschätzt wurde. Schlussfolgerung. Diese Studie zeigt, dass konventionelle Röntgenaufnahmen oftmals unverlässliche Informationen bezüglich der Klassifikation, der Gelenkflächenbeteiligung und der Fragmentgröße von Radiuskopffrakturen geben. Im Zweifel sollte die Indikation zur Durchführung einer zusätzlichen CT großzügig gestellt werden, um die Frakturkonstellation genauer zu beurteilen.

\section{Schlüsselwörter}

Radiusfrakturen · Röntgenstrahlen .

Computertomographie · Diagnostik . Röntgenaufnahmen percentage of intact radial head articular surface was calculated. By subtracting this value from $100 \%$, the percentage of articular fracture involvement was obtained.

To measure the size of the largest fracture fragment, the software ImagePro Plus 6.0 (IPP, Media Cybernetics, Inc, Rockville, MD) was used. In the axial plane, the two vertices of the respective fragment were connected by a line. This line was considered to be the length of the fragment (• Fig. 3a). Three parallel lines were then drawn perpendicularly to the aforementioned line. The mean value of the three parallel lines was considered to be the width of the fragment (- Fig. 3a). In the coronal plane, a line perpendicular to the articular surface of the fragment was drawn to evaluate the height of the fragment (- Fig. 3b). In situations where the coronal plane did not sufficiently display the fragment, the sagittal plane was used instead.
Three experienced trauma surgeons (M.H., K.W., L.P.M.) separately evaluated the blinded plain radiographs (anteroposterior view, lateral view, and radial head view) to determine the type of radial head fracture (according to the Mason classification), the percentage of articular involvement, and the size of the largest fracture fragment using the same guidelines. 


\begin{tabular}{|c|c|c|c|}
\hline \multicolumn{2}{|c|}{ Observer No } & \multirow{2}{*}{$\begin{array}{l}\text { Category } \\
\text { Perfect }\end{array}$} & \multirow{2}{*}{$\begin{array}{l}\text { Kappa } \\
1.0\end{array}$} \\
\hline 1 & 2 & & \\
\hline $1+2$ & 3 & Fair & 0.252 \\
\hline $1+2$ & 4 & Fair & 0.252 \\
\hline $1+2$ & 5 & Fair & 0.349 \\
\hline
\end{tabular}

\section{Statistical analysis}

Kappa values are commonly used to describe chance-corrected agreement in a variety of intra-observer and inter-observer studies [6-8]. In order to estimate agreement among intra-observer and inter-observer with respect to fracture classification, the kappa multirater measure (k) was applied. Siegel and Castellan calculated the agreement among observers with use of the kappa multi-rater measure [9]. Landis and Koch interpreted the Kappa values with use of the following guidelines [7]: Values of 0.01 to 0.20 indicate slight agreement; 0.21 to 0.40 , fair agreement; 0.41 to 0.60 , moderate agreement; 0.61 to 0.80 , substantial agreement; and 0.81 or more, almost perfect agreement. Zero indicates no agreement beyond that expected due to chance alone, -1.00 means total disagreement, and +1.00 represents perfect agreement $[7,8]$.

The differences between two groups were tested by the Wilcoxon test. Multiple group differences were tested by the Friedman test. The CT findings were used as a reference to calculate the overall sensitivity and specificity of radiographs. The median data of the results of the two rounds of observer 1 and observer 2 were considered to be the observer value. In order to compare the size of the fragments, the result of multiplying the data of length, width, and height was considered the volume in $\mathrm{mm}^{3}$. Value $Z$ stands for the numerical value of standardized normal distribution. The level of significance was set to $p<0.01$. SPSS for Windows version 17 (SPSS, Chicago, IL, USA) was applied to perform the statistical analysis.

\section{Results}

\section{Intra-/inter-observer reliability of CT measurements}

According to the Mason classification, observer 1 and 2 obtained the same results both for intra- and inter-observer testing.

The evaluation of articular fracture involvement and of fragment sizes did not reveal any significant differences regarding the intra- and inter-observer reliability of observers 1 and $2(p \geq 0.226)$.

\section{Inter-observer reliability of CT and plain radiographs}

Regarding fracture classification, the inter-observer agreement between CT evaluations and plain radiography evaluations was low. Additionally, only fair agreement was found between the observers evaluating plain radiographs. This was mainly due to the fact that many fractures appeared as Mason type 2 fractures on plain radiographs but were actually multi-fragmentary when evaluating the CT scan. The results are shown in $\bullet$ Table 1.

The size of the largest fracture fragment was underrated on the basis of plain radiography (• Fig.4). These results were statistically significant for all three observers $(p<0.01)$. The articular fracture involvement, however, tended to be overestimated (• Fig. 5). These results were statistically significant for observer 5 only $(p<0.01)$.

\section{Discussion}

The present study shows that CT scans produce reliable results regarding the evaluation of fracture classification, articular involvement, and fragment size of radial head fractures with high intraand inter-observer reliability. Only fair agreement was achieved regarding the inter-observer comparison of fracture classification between plain radiography and CT. In addition, inter-observer comparisons of the percentage of articular involvement and the size of the fracture fragments by means of plain radiography showed significant differences. This indicates that plain radiography has its limitations in the judgment of these three aspects.

Approximately $50 \%$ of radial head and neck fractures are non-displaced and more difficult to diagnose than displaced radial head fractures [10]. The quality of plain radiography can be limited due to the patients' symptoms and the inability to extend or move their elbow, which makes the interpretation of the images more difficult. As our data show, CT scans are of great help in avoiding misinterpretation of the fracture.

The reasons for the inaccuracy of plain radiography in the evaluation of radial head fractures include the presence of overlapping bones or soft tissue shadows, non-standardized radiographic posture, and obscured fracture lines in the early stage of trauma. Sormaala et al. [11] evaluated the correlation of the number and anatomical location of fractures in elbow dislocation, to study the association between the trauma energy and the direction of dislocation, and to compare the diagnostic accuracy of plain radiographs for fractures with multidetector CT (MDCT) scans. The authors concluded that the general sensitivity of the radiographs was $62 \%$ and the specificity was $96 \%$. In order to evaluate the degree of the fracture and to detect occult fractures, MDCT can be used as a reference standard. Auffarth et al. [12] assessed the inter-observer reliability of radiologic diagnoses after first-time traumatic shoulder dislocation with radiographs and CT images. For the diagnoses of glenoid rim fractures and Hill-Sachs lesions, radiographs showed great differences from CT images. For evaluating osseous lesions, CT was superior to radiographs, especially at the glenoid rim.

Nevertheless, plain radiography should remain the first-line imaging in elbow trauma as it is more economical, convenient, and produces less radiation and high spatial resolution images. When in doubt regarding the fracture pattern, a low threshold for an additional CT scan is recommended. 


\section{Limitations}

There are some limitations in the current study. First, the number of cases was limited. Second, in terms of size measurements, only the largest fragment was evaluated and measured. In addition, because of the irregular shapes of the fragments, the mean values were considered to constitute the width values of fragments in CT images. Third, several fragments were dislocated or rotated. This resulted in fragments deviating from their original anatomical axes. Therefore, the axes were determined according to the respective observer's experience. While this could reduce the accuracy of the measurements, excellent inter-observer reliability was observed.

\section{Practical conclusion}

\section{- Plain radiography remains the first- line imaging modality for the diagno- sis of radial head fractures. \\ - The present study shows, however, that the diagnostic accuracy of plain radiography may be lower than previously thought. \\ - Given its high inter- and intra-ob- server reliability, an additional com- puted tomography scan should be performed if there is any doubt.}

\section{Corresponding address}

PD Dr. Michael Hackl
Faculty of Medicine,
University of Cologne
Kerpener Straße 62,
50937 Cologne, Germany
michael.hackl@uk-koeln.de

Funding. Open Access funding enabled and organized by Projekt DEAL.

\section{Declarations}

Conflict of interest. Z. Zhao, Y. Lyu, T. Leschinger, K. Wegmann, L.P. Müller, and M. Hackl declare that they have no competing interests.

All procedures performed in studies involving human participants or on human tissue were in accordance with the ethical standards of the institutional and/or national research committee and with the 1975 Helsinki declaration and its later amendments or comparable ethical standards. Informed consent was obtained from all individual participants included in the study. This study was approved by the local institutional review board.

Open Access. This article is licensed under a Creative Commons Attribution 4.0 International License, which permits use, sharing, adaptation, distribution and reproduction in any medium or format, as long as you give appropriate credit to the original author(s) and the source, provide a link to the Creative Commons licence, and indicate if changes were made. The images or other third party material in this article are included in the article's Creative Commons licence, unless indicated otherwise in a credit line to the material. If material is not included in the article's Creative Commons licence and your intended use is not permitted by statutory regulation or exceeds the permitted use, you will need to obtain permission directly from the copyright holder. To view a copy of this licence, visit http://creativecommons.org/licenses/by/4.0/.

\section{References}

1. Rosas HG, Lee KS (2010) Imaging acute trauma of the elbow. Semin Musculoskelet Radiol 14(4):394-411

2. Hartman M, Steinman $S$ (2008) The radial head fractures. In: Celli L, Celli A, Morrey BF (eds) Treatment of elbow lesions: new aspects in diagnosis and surgical techniques. Springer, New York, pp 83-88

3. Mason ML (1954) Some observations on fractures of the head of the radius with a review of one hundred cases. BrJSurg 42(172):123-132

4. Johnston G (1962) A follow-up of one hundred cases of fracture of the head of the radius with a review of the literature. Ulster Med J31(1):51

5. Dalinka M, Boorstein J, Zlatkin M (1989) Computed tomography of musculoskeletal trauma. Radiol Clin North Am 27(5):933-944

6. Cohen J (1960) A coefficient of agreement for nominal scales. Educ Psychol Meas 20(1):37-46

7. Landis JR, Koch GG (1977) The measurement of observer agreement for categorical data. Biometrics 33(1):159-174

8. Posner KL, Sampson PD, Caplan RA, Ward RJ, Cheney FW (1990) Measuring interrater reliability among multiple raters: an example of methods for nominal data. Statist Med 9(9):1103-1115

9. Siegel S, Castellan N (1988) Nonparametric statistics for the behavioral sciences, 2nd edn. McGraw-Hill, New York

10. Rogers $L$ (1992) Radiology of skeletal trauma, 2nd edn. Churchill Livingstone, New York

11. Sormaala MJ, Sormaala A, Mattila VM, Koskinen SK (2014) MDCT findings after elbow dislocation: a retrospective study of 140 patients. Skelet Radiol 43(4):507-512

12. Auffarth A, Mayer M, Kofler B, Hitzl W, Bogner R, Moroder P, Korn G, Koller H, Resch H (2013) The interobserver reliability in diagnosing osseous lesions after first-time anterior shoulder dislocation comparing plain radiographs with computed tomography scans. J Shoulder Elbow Surg 22(11):1507-1513 